\title{
Terminy i definicje dotyczące wyznaczania poziomu halasu emitowanego przez pojazdy szynowe wg EN ISO 3095
}

\begin{abstract}
W ostatnich latach znacznie wzrosła aktywność w tworzeniu norm dotyczacych wykonywania pomiarów poziomu hałasu, w tym również dla taboru kolejowego. Ukazuja się nowe dyrektywy, rozporzadzenia i normy porzqdkujace ta dziedzinę. W artykule przedstawiono wersję oryginalnq oraz tlumaczenie i interpretację autorów aktualnych terminów i definicji dotyczqcych wyznaczania poziomu hałasu generowanego przez pojazdy szynowe.
\end{abstract}

\section{Wstęp}

Norma EN ISO 3095 [1] ujednolica przede wszystkim metodykę pomiarową hałasu kolejowego. Zdefiniowano $w$ niej 17 podstawowych pojęć związanych z pomiarem hałasu emitowanego przez pojazdy szynowe. Ustalono również warunki niezbędne do osiagnnięcia powtarzalnych i porównywalnych wyników pomiarów poziomów i widm hałasu emitowanego przez wszystkie rodzaje szynowych pojazdów kolejowych oraz wykorzystywanych w komunikacji miejskiej, za wyjątkiem pojazdów do utrzymania torów. Poza tym określono wielkości mierzone i przyrządy pomiarowe oraz warunki pomiarów i sposób postępowania podczas ich wykonywania. Podano formę opracowywania wyników i raportów z pomiarów.

Norma ma zastosowanie do :

- badań typu,

- okresowych badań monitorujących poziom hałasu. do:

Wyniki z pomiarów mogą mieć zastosowanie

- ustalenia charakterystyki hałasu emitowanego przez dane pojazdy szynowe

- porównywania hałasu emitowanego przez różne pojazdy na określonym odcinku toru

- gromadzenia informacji o podstawowych źródłach hałasu pojazdów szynowych.

W wykazie literatury przedstawiono dokumenty odniesienia $[5,6,7,8,9]$ konieczne do zastosowania normy [1]

Artykuł przedstawia nieoficjalne tłumaczenie normy dokonane przez autorów.

Zmierzone wartości powinny zostać odniesione m.in. do wartości dopuszczalnych opublikowanych w Dyrektywie 2006/66/WE [2] - TSI podsystem „Tabor kolejowy”, aspekt „Hałas”. Techniczna specyfikacja dla interoperacyjności obejmuje wartości dopuszczalne dla hałasu stacjonarnego, hałasu ruszania, hałasu przejazdu oraz hałasu w kabinie maszynisty, powodowanego przez konwencjonalny tabor kolejowy. TSI ma zastosowanie do nowych pojazdów oraz odnowionego lub zmodernizowanego taboru kolejowego (o ile jest to wymagane). TSI obejmuje: lokomotywy, zespoły trakcyjne, wagony towarowe (w tym tabor kolejowy przeznaczony do przewozu ciężarówek).

Poza tym uzyskane wyniki można przeanalizować zgodnie z wartościami dopuszczalnymi zawartymi w PN-92/K-11000 [3] a dla pomiarów środowiskowych zgodnie z Rozporządzeniem Ministra Środowiska z dnia 14 czerwca 2007r. w sprawie dopuszczalnych poziomów hałasu w środowisku [4].

\section{Terminy i definicje}

Numeracja poszczególnych definicji została przywołana zgodnie z normą. Pozwoli to na równoległe studiowanie artykułu $\mathrm{z}$ angielska wersją normy EN ISO 3095.

Definicje od 3.7 do 3.14 mają zastosowanie do wielkości mierzonych zarówno w widmie częstotliwości, jak i w określonych pasmach częstotliwości o częstotliwościach środkowych $\mathrm{f}$ (wyrażonych w Hz).

\section{1.}

train

single vehicle or a number of coupled vehicles/units operating on a guided ground transport system [EN 13452-1]

\section{Pociag}

Pojedynczy pojazd lub pewna liczba połączonych pojazdów/zespołów pracujących na prowadzonym naziemnie systemie transportowym.

\section{2.}

type test for noise emission of railbound vehicles type test 
measurement performed to prove that, or to check if, a vehicle delivered by the manufacturer complies with the noise specifications

Badania typu dla hatasu emitowanego przez, pojazdy szynowe

badania typu

Pomiary dokonywane, aby wykazać że/lub sprawdzić czy pojazdy dostarczone przez producenta są zgodne ze specyfikacjami dotyczącymi hałasu.

\section{3.}

monitoring test for noise emission of railbound vehicles monitoring test

measurement performed to check if the noise of a vehicle has changed since initial delivery or after modification

Badanie monitorujace hatas emitowany przez pojazdy szynowe

(badanie monitorujace)

Pomiary prowadzone w celu sprawdzenia czy hałas pojazdów zmienił się od pierwotnej dostawy lub po modernizacji.

\section{4.}

\section{environmental assessment test}

measurement performed for collecting data to be utilised in prediction method for environmental assessment

\section{Środowiskowe badania oceniajace}

Pomiary prowadzone w celu gromadzenia danych niezbędnych do prognozowania hałasu stosowanego do oceny środowiskowej.

\section{5.}

\section{roughness}

\section{$r$}

root mean square (RMS) value of the amplitude variation of the running surface of a rail in the direction of motion (longitudinal level) measured over a rail length, expressed in $\mu \mathrm{m}$

\section{Chropowatość}

Wartość skuteczna (RMS) amplitudy odchylenia powierzchni jezdnej szyny w kierunku ruchu mierzona wzdłuż długości szyny, wyrażona w $\mu \mathrm{m}$.

\section{6.}

\section{roughness level}

$L_{r}$

level given by the equation:

$$
L_{r}=10 \cdot \lg \left(\frac{r^{2}}{r_{0}^{2}}\right) d B
$$

where

$L_{r} \quad$ is the roughness level in $\mathrm{dB}$;

$r \quad$ is the RMS roughness in $\mu \mathrm{m}$;

$r_{0} \quad$ the reference roughness; $r 0=1 \mu \mathrm{m}$.

This definition applies to values measured either as a wavelength spectrum or in a particular wavelength band centred at $\lambda$ (expressed in $\mathrm{m}$ ).

\section{Poziom chropowatości \\ $L_{r}$}

Poziom chropowatości otrzymywany ze wzoru:

$$
L_{r}=10 \cdot \lg \left(\frac{r^{2}}{r_{0}^{2}}\right) d B
$$

gdzie:

$L_{r} \quad$ poziom chropowatości [dB];

$r \quad$ wartość skuteczna (RMS) chropowatości $[\mu \mathrm{m}]$;

$r_{0} \quad$ chropowatość odniesienia; $\mathrm{r}_{0}=1 \mu \mathrm{m}$.

Definicja ta dotyczy wartości zmierzonych zarówno dla widma długości fali, jak i dla określonego środkowego pasma długości fali $\lambda$ (wyrażony $\mathrm{w} \mathrm{m}$ ).

\section{7.}

\section{sound pressure}

$p(t)$

root mean square (RMS) value of a fluctuating pressure superimposed on the static atmospheric pressure measured over a certain time period, expressed in $\mathrm{Pa}$

\section{Ciśnienie akustyczne}

$p(t)$

definiowane jako wartość skuteczna (RMS), zmiennego ciśnienia odniesionego do ciśnienia atmosferycznego zmierzonego w pewnym przedziale czasu, wyrazone $\mathrm{w}[\mathrm{Pa}]$.

3.8.

sound pressure level

$L_{p}$

level given by the equation:

$$
L_{p}=10 \cdot \lg \left(\frac{p(t)^{2}}{p_{0}{ }^{2}}\right) d B
$$

where

$$
\begin{array}{ll}
L_{p} & \text { is the sound pressure level in } \mathrm{dB} ; \\
p(t) & \text { is the RMS sound pressure in } \mathrm{Pa} ; \\
p_{0} & \text { the reference sound pressure; } 2 \times 10^{-} \\
& { }^{5} \mathrm{~Pa}(=20 \mu \mathrm{Pa}) .
\end{array}
$$




\section{Poziom ciśnienia akustycznego}

$L_{p}$

Poziom wyrażony równaniem:

$$
L_{p}=10 \cdot \lg \left(\frac{p(t)^{2}}{p_{0}^{2}}\right) d B
$$

gdzie

$L_{p} \quad$ poziom ciśnienia akustycznego $\mathrm{w}$ [dB]

$p(t) \quad$ ciśnienie akustyczne $\mathrm{w} \mathrm{Pa}$, definiowane jako wartość skuteczna ciśnienia akustycznego (RMS),

$p_{0} \quad$ ciśnienie akustyczne odniesienia równe $2 \times 10^{-5} \mathrm{~Pa}(=20 \mu \mathrm{Pa})$.

3.9.

\section{A-weighted sound pressure level $L_{p A}$}

sound pressure level obtained by using the frequency weighting A (see EN 61672 -1 and EN 61672-2), given by the following equation:

$$
L_{p A}=10 \cdot \lg \left(\frac{p_{A}(t)^{2}}{p_{0}{ }^{2}}\right) d B
$$

where

$$
\begin{array}{ll}
L_{p A} & \begin{array}{l}
\text { is the A-weighted sound pressure } \\
\text { level in } \mathrm{dB} ;
\end{array} \\
p_{A}(t) \quad \begin{array}{l}
\text { is the RMS A-weighted sound pres- } \\
\text { sure in } \mathrm{Pa} ;
\end{array} \\
p_{0} \quad \begin{array}{l}
\text { the reference sound pressure; } p 0=20 \\
\mu \mathrm{Pa} .
\end{array}
\end{array}
$$

\section{$\underline{\text { Poziom dźwięku } A}$}

\section{$L_{p A}$}

Poziom ciśnienia akustycznego dźwięku skorygowanego według charakterystyki częstotliwościowej A (zobacz EN 61672 - 1 i EN 61672 - 2), wyznaczany $\mathrm{z}$ równania:

$$
L_{p A}=10 \cdot \lg \left(\frac{p_{A}(t)^{2}}{p_{0}{ }^{2}}\right) d B
$$

gdzie

$L_{p A} \quad$ - poziom dźwięku A w dB

$p_{A}(t)$ - ciśnienie akustyczne w paskalach [Pa], definiowane jako wartość skuteczna ciśnienia akustycznego (RMS) dźwięku skorygowanego według charakterystyki częstotliwościowej A

$p_{0} \quad$ - ciśnienie akustyczne odniesienia równe $2 \times 10^{-5} \mathrm{~Pa}(=20 \mu \mathrm{Pa})$.
3.10.

AF-weighted maximum sound pressure level

$L_{p A F \max }$

maximum value of the A-weighted sound pressure level determined during the measurement time interval $T$ by using time weighting $\mathrm{F}$ (fast)

[EN 61672-1]

\section{Maksymalnv poziom dźwieku A ze stala czasowa $F$} $\underline{(F A S T)}$

$L_{p A F \max }$

Maksymalna wartość poziomu dźwięku A zaobserwowana podczas pomiaru $\mathrm{w}$ przedziale czasu $\mathrm{T}$ przy zastosowaniu stałej czasowej F (FAST)

[EN 61672-1]

\subsection{1.}

A-weighted equivalent continuous sound pressure $\underline{\text { level }}$

$L_{p A e q, T}$

A-weighted sound pressure level given by the following equation:

$$
L_{p A e q, T}=10 \lg \left(\frac{1}{T} \int_{0}^{T} \frac{p_{A}^{2}(t)}{p_{0}^{2}} d t\right) d B
$$

where

$L_{p A e q, T}$ is the A-weighted equivalent continuous sound pressure level in $\mathrm{dB}$;

$T \quad$ is the measurement time interval in s;

$p_{A}(t)$ is the A-weighted instantaneous sound pressure in $\mathrm{Pa}$;

$p_{0} \quad$ the reference sound pressure; $2 \times 10^{-}$ ${ }^{5} \mathrm{~Pa}(=20 \mu \mathrm{Pa})$

NOTE Adapted from ISO 1996-1:2003.

\section{$\underline{\text { Równoważny poziom dźwięku } A}$}

$L_{p A e q, T}$

Równoważny poziom dźwięku A wyznaczany z równania:

$$
L_{p A e q, T}=10 \lg \left(\frac{1}{T} \int_{0}^{T} \frac{p_{A}^{2}(t)}{p_{0}^{2}} d t\right) d B
$$

gdzie:

$$
\begin{aligned}
& L_{p A e q, T} \text { równoważny poziom dźwięku } \\
& \text { A w }[\mathrm{dB}] \text {; } \\
& T \quad \text { czas pomiaru lub obserwacji w s; } \\
& p_{A}(t) \quad \text { chwilowe ciśnienie akustyczne w [Pa] } \\
& \text { skorygowane według charakterystyki } \\
& \text { częstotliwościowej A } \\
& p_{0} \quad \text { ciśnienie akustyczne odniesienia rów- } \\
& \text { ne } 2 \times 10^{-5} \mathrm{~Pa}(=20 \mu \mathrm{Pa})
\end{aligned}
$$




\subsection{2.}

A-weighted equivalent continuous sound pressure level on the pass-by time

$L_{p A e q, T p}$

A-weighted sound pressure level given by the following equation:

$$
L_{p A e q, T_{p}}=10 \lg \left(\frac{1}{T_{2}-T_{1}} \int_{T_{1}}^{T_{2}} \frac{p_{A}^{2}(t)}{p_{0}^{2}} d t\right) d B
$$

where

$L_{p A e q, T}$ is the A-weighted equivalent continuous sound pressure level on the pass-by time in $\mathrm{dB}$;

$T_{p}=T_{2}-T_{1}$ is the measurement pass-by time interval beginning at $T 1$ and ending at $T 2$ in $\mathrm{s}$, see Figure 1;

$p_{A}(t)$ is the A-weighted instantaneous sound pressure in $\mathrm{Pa}$;

$p_{0} \quad$ the reference sound pressure; $p 0=20 \mu \mathrm{Pa}$.

\section{$\underline{\text { Równoważny poziom dźwieku A podczas jazdy }}$}

\section{$L_{p A e q, T p}$}

Równoważny poziom dźwięku A podczas jazdy wyznaczany $z$ równania:

$$
L_{p A e q, T_{p}}=10 \lg \left(\frac{1}{T_{2}-T_{1}} \int_{T_{1}}^{T_{2}} \frac{p_{A}^{2}(t)}{p_{0}^{2}} d t\right) d B
$$

gdzie:

$$
\begin{aligned}
& L_{p A e q, T p} \quad \text { równoważny poziom dźwięku } \\
& \text { A podczas jazdy w dB; } \\
& T_{p}=T_{2}-T_{1} \quad \text { ustalony przedział czasu, do- } \\
& \text { statecznie dhugi dla objęcia } \\
& \text { znaczącej akustycznie części } \\
& \text { zdarzenia dźwiękowego od } \\
& \text { punktu } \mathrm{T}_{1} \text { do punktu } \mathrm{T} 2 \mathrm{w} \text { [s], } \\
& \text { zobacz rys. 1; } \\
& p_{A}(t) \quad \text { chwilowe ciśnienie akustycz- } \\
& \text { ne w }[\mathrm{Pa}] \text { skorygowane we- } \\
& \text { dług charakterystyki często- } \\
& \text { tliwościowej A } \\
& p_{0} \quad \text { ciśnienie akustyczne odnisie- } \\
& \text { nia równe } 2 \times 10^{-5} \mathrm{~Pa} \quad(=20 \\
& \mu \mathrm{Pa}) \text {. }
\end{aligned}
$$

3.13.

\section{single event level \\ SEL}

A-weighted sound level of a single event measured for a time interval $T$ and normalised to $T 0=1 \mathrm{~s}$. The time interval $T$ will be long enough to include all the acoustic energy related to the event, considering at least the points at $-10 \mathrm{~dB}$ below the lower $L \mathrm{pA}$ during $T$. SEL is given by the following equation:

$$
S E L=10 \lg \left(\frac{1}{T_{0}} \int_{0}^{T} \frac{p_{A}^{2}(t)}{p_{0}^{2}} d t\right) d B
$$

where

SEL is the A-weighted sound exposure level in $\mathrm{dB}$;

$T_{0}=1 s$ is the reference time interval;

$T \quad$ is the measurement time interval in s;

$p_{A}(t)$ is the A-weighted instantaneous sound pressure in $\mathrm{Pa}$;

$p_{0} \quad$ the reference sound pressure; $p_{0}=20 \mu \mathrm{Pa}$. single event level, SEL, is related to the A-weighted equivalent continuous sound pressure level, $L \mathrm{pAeq}, \mathrm{T}$, by the following equation:

$$
S E L=L_{p A e q, T}+10 \lg \left(\frac{T}{T_{0}}\right) d B
$$

\section{Poziom ekspozycyiny pojedynczego zdarzenia}

\section{SEL}

Poziom dźwięku skorygowanego według charakterystyki częstotliwościowej A pojedynczego zdarzenia mierzony $\mathrm{w}$ przedziale czasu $\mathrm{T}$ i znormalizowany do czasu odniesienia $T_{0}=1 \mathrm{~s}$. Przedział czasu pomiaru $\mathrm{T}$ powinien być na tyle długi aby zawierał energie akustyczną bliską zdarzeniu, uwzględniając co najmniej punkty powyżej wartości $\mathrm{L}_{\mathrm{pAFmax}}-10 \mathrm{~dB}$ w przedziale czasu T. SEL otrzymujemy z następującego wzoru:

$$
S E L=10 \lg \left(\frac{1}{T_{0}} \int_{0}^{T} \frac{p_{A}^{2}(t)}{p_{0}^{2}} d t\right) d B
$$

gdzie:

SEL poziom ekspozycji na hałas, skorygowany według charakterystyki częstotliwościowej A w dB

$T_{0}=1 s$ czas odniesienia;

$T \quad$ czas pomiaru w s;

$p_{A}(t)$ chwilowe ciśnienie akustyczne w $\mathrm{Pa}$ skorygowane według charakterystyki częstotliwościowej A

$p_{0} \quad$ ciśnienie akustyczne odniesienia równe $2 \times 10^{-5} \mathrm{~Pa}(=20 \mu \mathrm{Pa})$ 
Poziom pojedynczego zdarzenia SEL jest powiązany $\mathrm{z}$ równoważnym poziomem dźwięku $\mathrm{A}, \mathrm{L}_{\mathrm{pAeq}, \mathrm{T}}$, poprzez następujące równanie:

$$
S E L=L_{p A e q, T}+10 \lg \left(\frac{T}{T_{0}}\right) d B
$$

3.14.

\section{transit exposure level}

TEL

A-weighted sound level of a train passage, measured for a time interval $T$ and normalised to the pass-by time

$T \mathrm{p}$. The time interval $T$ will be long enough to include all the acoustic energy related to the event, considering at least the points at $-10 \mathrm{~dB}$ below the lower $L \mathrm{pA}$ during Tp. TEL is given by the following equation:

$$
T E L=10 \lg \left(\frac{1}{T_{p}} \int_{0}^{T} \frac{p_{A}^{2}(t)}{p_{0}^{2}} d t\right) d B
$$

where

TEL is the A-weighted transit exposure level in $\mathrm{dB}$;

$T \quad$ is the measurement time interval in s;

$T_{p} \quad$ is the pass-by time of the train in seconds which is the overall length of the train divided by the train speed;

$p_{A}(t)$ is the A-weighted instantaneous sound pressure in $\mathrm{Pa}$;

$p_{0} \quad$ the reference sound pressure; $p_{0}=20$ $\mu \mathrm{Pa}$.

transit exposure level, TEL, is related to single event level, SEL, and to the A-weighted equivalent continuous sound pressure level, $\mathrm{L}_{\mathrm{pAeq}, \mathrm{T}}$ by the following equations:

$$
\begin{aligned}
& \text { and } \\
& \text { TEL }=S E L+10 \lg \left(T_{0} / T_{p}\right) \\
& T E L L_{p A e q, T}+10 \lg \left(T / T_{p}\right)
\end{aligned}
$$

where $T_{0}=1 \mathrm{~s}$ is the reference time interval

\section{Poziom ekspozvcvinv przejazdu \\ TEL}

Poziom dźwięku skorygowanego według charakterystyki częstotliwościowej A przejazdu pociąu, mierzony w przedziale czasu $T$ i odniesiony do czasu przejazdu $T_{p}$.

Przedział czasu pomiaru $T$ powinien być na tyle długi aby zawierał energię akustyczną bliską zdarzeniu, uwzględniając co najmniej punkty o wartości powyżej -10 dB od najniższej wartości $L_{p A}$ zaobserwowanej w przedziale czasu $T_{p}$.
TEL otrzymujemy z następującego równania:

$$
T E L=10 \lg \left(\frac{1}{T_{p}} \int_{0}^{T} \frac{p_{A}^{2}(t)}{p_{0}^{2}} d t\right) d B
$$

gdzie:

TEL ekspozycyjny poziom przejazdu, skorygowany według charakterystyki częstotliwościowej A w dB;

$T$ czas pomiaru w s;

$T_{p} \quad$ czas przejazdu pociagu w sekundach, który jest całkowitą długością pociagu podzieloną przez prędkość pociagu

$p_{A}(t)$ chwilowe ciśnienie akustyczne w $\mathrm{Pa}$ skorygowane według charakterystyki częstotliwościowej A

$p_{0} \quad$ ciśnienie akustyczne odniesienia równe $2 \times 10^{-5} \mathrm{~Pa}(=20 \mu \mathrm{Pa})$

ekspozycyjny poziom przejazdu, TEL, jest powiązany z poziomem pojedynczego zdarzenia, SEL, i równoważnym poziomem dźwięku A, $\mathrm{L}_{\mathrm{pAeq}, \mathrm{T}}$, poprzez następujące równania:

$$
\begin{aligned}
& T E L=S E L+10 \lg \left(T_{0} / T_{p}\right) \\
& \text { oraz } \\
& T E L=L_{p A e q, T}+10 \lg \left(T / T_{p}\right)
\end{aligned}
$$

gdzie $T_{0}=1 s$ jest przedziałem czasu odniesienia

\subsection{5.}

\section{measurement time interval $T$, and train pass-by time} $T \mathrm{p}$

Measurement time interval, $T$, is chosen, so the measurement starts when the A-weighted sound pressure level is $10 \mathrm{~dB}$ lower than found when the front of the train is opposite the microphone position. The measurement is stopped when the A-weighted sound pressure level is $10 \mathrm{~dB}$ lower than found when the rear of the train is opposite the microphone position.

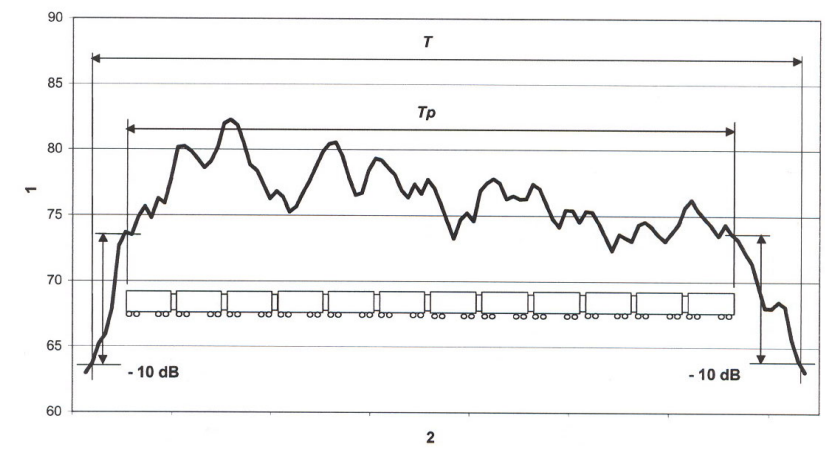

Key

1 A-weighted sound pressure level, dB

2 Time

Figure 1 - Example of selection of measuring time interval, $T$, for a whole train 
NOTE The example illustrates the need for an independent device for measuring the train passage time, as the time cannot be deduced from the sound pressure level versus time.

For measurement of vehicle(s), which form part of a train, the measurement time interval $T$ is the passing time $T p$ of the vehicle(s) under test. For the measurement of un-powered vehicles, the measurement time interval $T$ begins when the centre of the first vehicle under test passes in front of the microphone position and ends when the centre of the last vehicle under test passes in front of the microphone position. Figure 2 shows the required measurement time interval $T$ or the measurement of a single un-powered vehicle. Furthermore, it shows an example of the A-weighted sound pressure level, $L \mathrm{pA}$, time history for the passage of a train.

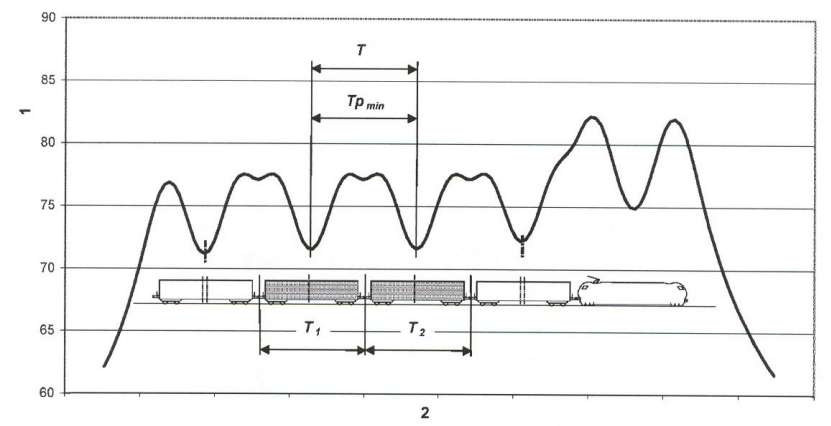

Key

1 A-weighted sound pressure level, dB

2 Time

Figure 2 - Example of selection of measuring time interval, $T$, for parts of a train

\section{pomiar przedzialu czasu $T$ i czasu przejazdu pociagu $\mathbf{T}_{\mathrm{p}}$}

Pomiar przedziału czasu $\mathrm{T}$ jest wybieralny, dlatego pomiar rozpoczyna się kiedy poziom ciśnienia akustycznego skorygowanego według charakterystyki częstotliwościowej A jest o $10 \mathrm{~dB}$ niższy niż stwierdzony kiedy czoło pociagu jest naprzeciwko położenia mikrofonu. Pomiar jest zakończony kiedy poziom ciśnienia akustycznego skorygowanego według charakterystyki częstotliwościowej A jest o $10 \mathrm{~dB}$ niższy niż stwierdzony kiedy tył pociągu jest naprzeciwko położenia mikrofonu.

UWAGA Przykład ilustruje potrzebę zastosowania niezależnego przyrządu (np. stopera) do pomiaru czasu przejazdu pociagu, w przeciwnym razie czas nie może być wnioskowany z przebiegu zmian poziomu ciśnienia akustycznego.

Dla pomiarów pojazdu(ów) stanowiących część pociagu, czas pomiaru $\mathrm{T}$ jest czasem przejazdu $T_{p}$ pojazdu(ów) podczas badań.

Dla pomiarów pojazdów nienapędnych, pomiar przedziału czasu $T$ rozpoczyna się kiedy środek pierwszego pojazdu podczas badań przejeżdża naprzeciwko mikrofonu i kończy się kiedy środek ostatniego pojazdu podczas badań przejeżdża naprzeciwko mikrofonu. Rysunek 2 przedstawia pomiar wymaganego przedziału czasu $\mathrm{T}$ lub pomiar pojedynczego nienapędnęgo pojazdu. Poza tym pokazuje przykład poziomu ciśnienia akustycznego skorygowany według charakterystyki częstotliwościowej $\mathrm{A}, L_{p A}$ przebiegu czasu dla przejazdu pociagu.

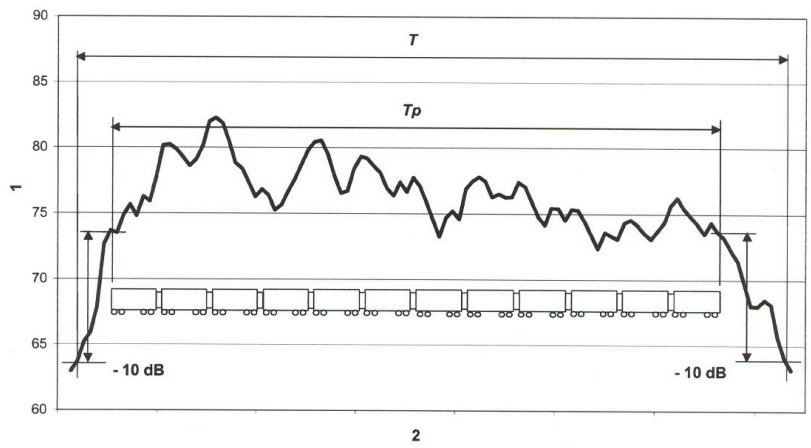

Legenda (opis osi)

1 Poziom ciśnienia akustycznego skorygowany według 2 Czas charakterystyki częstotliwościowej A, dB

Rys. 1 Przykład wybranego przedziału czasu T, dla całego pociagu

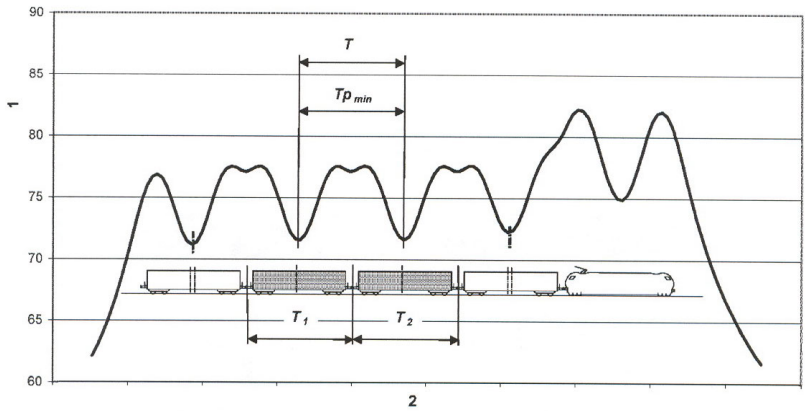

Legenda (opis osi)

1 Poziom ciśnienia akustycznego skorygowany według charakterystyki częstotliwościowej A, dB

2 Czas

Rys. 2 Przykład wybranego przedziału czasu T, dla części pociagu

3.16.

\section{noise with impulsive character}

noise which contains an isolated event or a series of such events. The impulsive character is conventionally confirmed if the difference between $L \mathrm{pAleq}, T$ and $L$ pAeq, $T$ is greater than $3 \mathrm{~dB}$ [EN ISO 12001]

\section{Halas o charakterze impulsowym}

Hałas impulsowy to hałas, który zawiera wyodrębnione zdarzenia akustyczne lub serię podobnych zdarzeń - wyróżnialnych w dynamice przebiegu czasowego zmian poziomu dźwięku.

Według PN-ISO 1996-2:1999/A1:2002 [10] „Akustyka - Opis i pomiary hałasu środowiskowego. Zbieranie danych dotyczacych sposobu zagospodarowania terenu (zmiana A1)" do wyznaczenia równoważnego 
Poprawka impulsowa do wyników pomiarów parametrów impulsów[dB]

Tabela 1

\begin{tabular}{|l|c|c|}
\hline Rodzaj dźwięku & $\begin{array}{c}\text { Pomiar ekspozycyjnych poziomów } \\
\text { dźwięku w odniesieniu do pojedyn- } \\
\text { czych impulsów }\end{array}$ & $\begin{array}{c}\text { Pomiar równoważnego poziomu } \\
\text { dźwięku impulsowego }\end{array}$ \\
\hline Typowy dźwięk impulsowy & $\mathbf{5}$ & $\mathbf{3}$ \\
\hline Dźwięk o dużej impulsowości & $\mathbf{1 2}$ & $\mathbf{1 1 , 7}$ \\
\hline Dźwięk impulsowy o dużej energii & $\mathbf{1 5}$ & $\mathbf{1 4 , 9}$ \\
\hline
\end{tabular}

poziomu dźwięku A z korekcją na impulsowość hałasu należałoby stosować następujące wartości poprawek impulsowych przedstawionych w tabeli 1 .

\subsection{7.}

noise with tonal character

noise which contains audible tones

\section{Hatas o charakterze tonalnym}

Hałas tonalny to hałas, który zawiera słyszalne tony (charakterystyczne częstotliwości identyfikujące badany dźwięk) - wyróżnialne w widmie częstotliwościowym badanego hałasu - tercjowym lub wąskopasmowym (FFT).

Według PN-ISO 1996-2:1999 [11] „Akustyka - Opis i pomiary hatasu środowiskowego. Zbieranie danych dotyczacych sposobu zagospodarowania terenu" do wyznaczenia równoważnego poziomu dźwięku A z korekcją na tonalność hałasu należałoby stosować następujące wartości poprawek tonalnych:

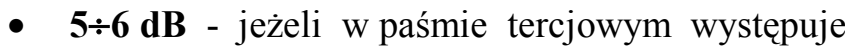
poziom ciśnienia akustycznego większy o co najmniej $5 \mathrm{~dB}$ niż w pasmach sąsiednich,

- $\quad \mathbf{2} \div \mathbf{3 ~ d B}-$ jeżeli tonalność jest stwierdzona tylko przez obserwatora lub na podstawie analizy wąskopasmowej (FFT).

\section{Podsumowanie}

Ujednolicenie stosowanych wskaźników zapewnia porównywalność wyników uzyskiwanych przez różne zespoły badawcze oraz pozwala na wprowadzenie norm akustycznych dotyczących zagadnień emisji hałasu od pojazdów szynowych.

Na szczególną uwagę zasługuje wprowadzenie definicji czasu przejazdu $T_{p}$ (intuicyjnej) oraz czasu pomiaru $\mathrm{T}$.

Należy również zauważyć istotne różnice pomiędzy poziomem ekspozycyjnym przejazdu TEL a poziomem ekspozycyjnym pojedynczego zdarzenia SEL.

Prowadzone prace normalizacyjne pozwolą również na uwzględnianie uciążliwości hałasu związanej $\mathrm{z}$ występowaniem tonalnych oraz impulsowych składowych hałasu.

\section{Literatura}

[1] EN ISO 3095 „Kolejnictwo - Akustyka Pomiar hałasu emitowanego przez pojazdy szynowe"

[2] Dyrektywa 2006/66/WE dotyczqca technicznej specyfikacji dla interoperacyjności odnoszqcej sie do podsystemu „tabor kolejowy - hałas” transeuropejskiego systemu kolei konwencjonalnych

[3] PN-92/K-11000 „Tabor kolejowy - Hatas Ogólne wymagania i badania"

[4] Rozporzadzenie Ministra Środowiska z dnia 14 czerwca 2007r. w sprawie dopuszczalnych poziomów hałasu w środowisku

[5] EN 60942, Elektroakustyka - Kalibratory dźwięku (IEC 60942:2003)

[6] EN 61260, Elektroakustyka - Filtry dla pasma oktawowego i pasma tercjowo - oktawowego (IEC 60942: 2003)

[7] EN 61672-1, Elektroakustyka - Mierniki poziomu dźwięku - Część 1: Wymagania techniczne (IEC 61672-1:2002)

[8] EN 61672-2, Elektroakustyka - Mierniki poziomu dźwięku - Część 2: Badania modelu wzor cowego (IEC 61672-2:2003)

[9] EN ISO 266, Akustyka - Preferowane częstotliwości (ISO 266:1997)

[10] PN-ISO 1996-2:1999/A1:2002 „Akustyka Opis i pomiary hałasu środowiskowego. Zbieranie danych dotyczacych sposobu zagospodarowania terenu (zmiana A1)"

[11] PN-ISO 1996-2:1999 „Akustyka - Opis i pomiary hatasu środowiskowego. Zbieranie danych dotyczacych sposobu zagospodarowania terenu" 